\title{
Lunotrikuetral eklem problemleri
}

\section{Lunotriquetral joint disorders}

\author{
İsmail Bülent Özçelik¹, Osman Orman² \\ ${ }^{1}$ El İstanbul El Cerrahi Mikrocerrahi Grubu, Yeni Yüzyıl Üniversitesi, El Cerrahisi Kliniği, Nişantaşı Üniversitesi \\ Sağlık Meslek Yüksek Okulu, İstanbul \\ ${ }^{2}$ SBÜ Metin Sabancı Baltalimanı Kemik Hastalıkları Eğitim ve Araştırma Hastanesi, El Cerrahisi Kliniği, İstanbul
}

\begin{abstract}
Lunotrikuetral (LT) eklem sorunları ulnar tarafın önemli ağrı sebeplerindendir. Muayenede LT eklem üzeri hassasiyet ve eklemde instabilite saptanabilir. Provokatif muayene testlerinde lunatum ile trikuetrum arasında hareketlenmenin varlığı test edilir. Manyetik rezonans (MR) görüntüleme LT eklemi değerlendirmekte her zaman yeterli bulgu vermeyebilir. MR artrografiler, dinamik radyografi incelemeleri ve kinematik bilgisayarlı tomografi (BT) incelemeleri tanı koymada yardımcı olmakla birlikte tanı için artroskopi altın standarttır. LT eklem yırtıkları kronik dönemde volar interkale segmental instabiliteye (VISI) ilerler. VISI, skafoid ve lunatumun daha fleksiyon, trikuetrumun daha ekstansiyon pozisyonuna gelmesidir. Tedavide planlama lezyonun akut veya kronik olmasına, travmatik ya da dejeneratif olmasına, beraberinde perilunat instabilite veya karpal çökme varlığına göre değişir. Cerrahi seçenekler artroskopik veya açık LT eklem debridmanı, LT ligament tamiri veya rekonstrüksiyonu, dorsal ligamentokapsülodez ve LT eklem artrodezidir.
\end{abstract}

Anahtar sözcükler: lunotrikuetral eklem; volar interkale segmental instabilite; Geissler sınıflaması; dorsal ligamentokapsülodez;

lunotrikuetral eklem artrodezi

\begin{abstract}
Lunotriquetral (LT) joint disorders are among the reasons of ulnar side pain. At examination of LT joint, tenderness and stability should be checked. Additionally, provocative tests should be performed. In these tests, the presence of movement between the lunate and triquetrum is evaluated. Magnetic resonance imaging (MRI) may not always provide sufficient findings to evaluate the LT joint. While MR arthrography, dynamic radiographic examinations and kinematic computed tomography (CT) examinations are helpful in diagnosis; arthroscopy is the gold standard for diagnosis. Ligament ruptures of the LT joint progress to Volar Intercalated Segmental Instability (VISI) in chronic period. VISI is becoming of scaphoid and lunate to more flexed and triquetrum to more extended position. Planning of the treatment varies according to whether LT joint disorder is acute or chronic, traumatic, or degenerative, and the presence of perilunate instability or carpal collapse. Surgical options are arthroscopic or open LT debridement, repair or reconstruction of LT ligament, dorsal ligament capsulodesis and LT joint arthrodesis.
\end{abstract}

Key words: lunotriquetral joint; volar intercalated segmental instability; Geissler classification; dorsal ligamentocapsulodesis; lunotriquetral joint arthrodesis

\section{LUNOTRIKKUETRAL EKLEM HASTALIKLARI}

Lunotrikuetral (LT) eklem hastalıkları nadir olmayan, beraberinde başka sorunları da barındıran ve sıklıkla gözden kaçırılan ulnar taraf ağrı sebeplerindendir.

\section{Anatomi ve Biyomekanik}

Lunotrikuetral eklemin stabilitesinden başlıca lunotrikuetral interosseöz bağ sorumludur. LT bağ C-şeklindedir ve üç bölümden oluşur: Dorsal fibröz, volar fibröz ve proksimal membranöz. Volar fibröz kısım daha kalındır ve LT eklem stabilitesinde daha önemlidir. Volar kısma volar ulnokarpal bağdan lifler katılır. Dorsal fibröz bölüm daha incedir ve üzerindeki dorsal radyokarpal bağdan lifler alır. Dorsal fibröz bölüm başlıca rotasyonel stabiliteden sorumludur. Membranöz kısmı avaskülerdir ve biyomekanik önemi yoktur (Şekil 1). ${ }^{[1-3]}$

Ulnokarpal bağlar; ulnotrikuetral ve ulnolunat bağ, "V" şeklindeki dağılımlarıyla, LT eklem stabilitesinde rol oynarlar. Bağların proksimale doğru çekmesiyle lunatum ve trikuetrum birbirine doğru yaklaşır. ${ }^{[4]}$

- İletişim adresi: Op. Dr. Osman Orman, Baltalimanı, Baltalimanı Hisar Cd. No: 62, 34470 Sarıyer, İstanbul

Tel: 0532 - 6553633 e-posta: osmanorman@gmail.com

- Geliş tarihi: 9 Mayıs $2021 \quad$ Kabul tarihi: 15 Mayıs 2021

ORCID iD: İsmail Bülent Özçelik, 0000-0002-0483-4956 • Osman Orman, 0000-0002-9177-2457 


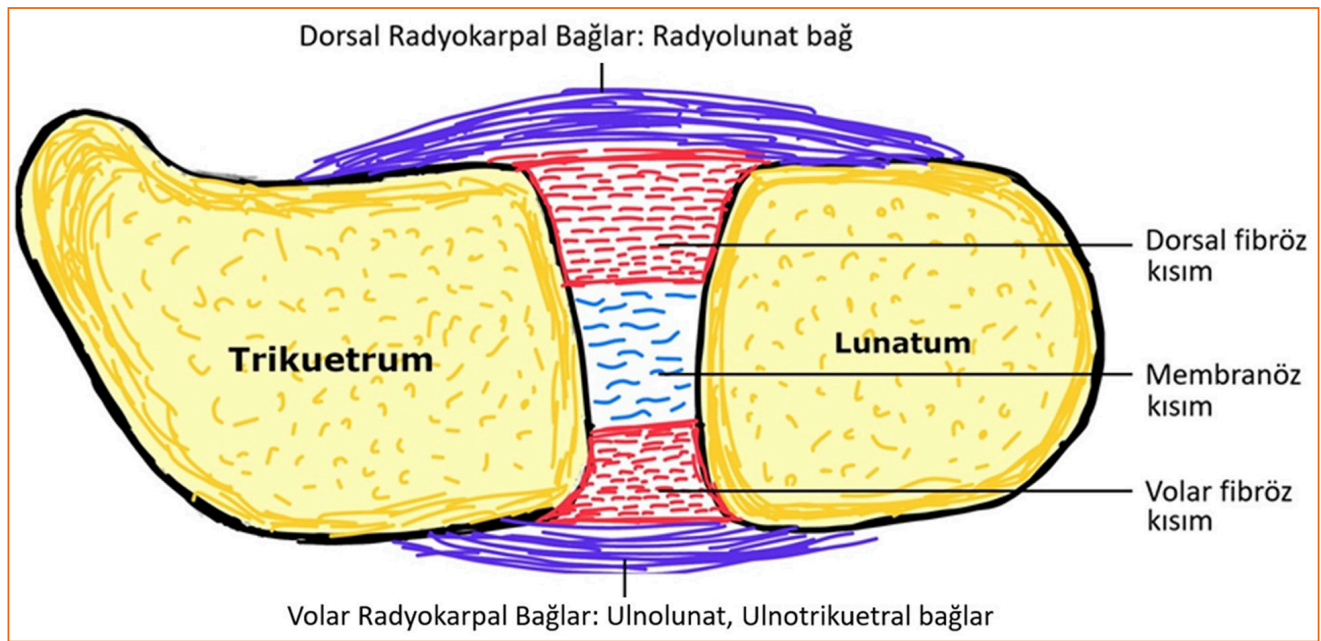

Şekil 1. Lunotrikuetral eklem aksiyel kesiti.

Trikuetrum, bağların en fazla yapıştığı, el bileğinin en stabil kemiğidir. Ön kol rotasyonu esnasında el bileği stabilitesi açısından eksen görevi görür. Ayrıca, el bileğinin pronosupinasyonu sırasında ana stabilizatördür. Trikuetrumun stabilitesi, intrinsik ve ekstrinsik bağlarla sağlanır. İntirinsik bağlar; karpal kemikler arasında uzanan lunotrikuetral interosseöz ve trikuetrohamat bağlardır. Ekstrinsik bağlarsa ön kol ile karpus arasında uzanan dorsal radyokarpal, volar radyoulnar, ulnotrikuetral ve ulnolunat bağlardır. ${ }^{[4]}$

El bileğinin fonksiyonelliğinde önemli katkısı olan hareketler fleksiyon ve ekstansiyon, ulnar ve radyal deviasyon, kısmen de pronasyon ve supinasyondur. Tüm bu hareketler el bileğinin fonksiyonel kompleks hareketi olan dart atma hareketinde rol alır. Proksimal sıranın interkalar (arada kalan) olması ve el bileği hareketlerine göre adapte olması hem stabilite hem hareketlilik sağlar. Proksimal sıranın eklem yüzlerinin uyumluluğu ve el bilek bağlarının yerleşimi de stabiliteye ve hareketliliğe katkı sağlayan diğer unsurlardır. ${ }^{[3-5]}$

Lunatum, skafoid etkisi altında daha fazla fleksiyona, trikuetrum etkisi ile daha fazla ektansiyona gitmeye zorlanır. Lunatum, normalde skafoidin aşırı fleksiyona ve trikuetrumun ekstansiyona gitmesini önler. Skafoid ile lunotrikuetral blok arası ilişki koparsa skafoid aşırı fleksiyona, lunotrikuetrum ise ekstansiyona gider; Dorsal interkale segmental instabilite (DISI) gelişir (Skafolunat ayrışma ya da skafoid kaynamamalarında olduğu gibi). Trikuetrum ile skafolunat blok arası ilişki koptuğunda ise trikuetrum ekstansiyona, skafolunat blok aşırı fleksiyona gider; kronik LT bağ yırtık ve instabilitelerinde volar interkale segmental instabilite (VISI) gelişir (Şekil 2). ${ }^{[4-5]}$

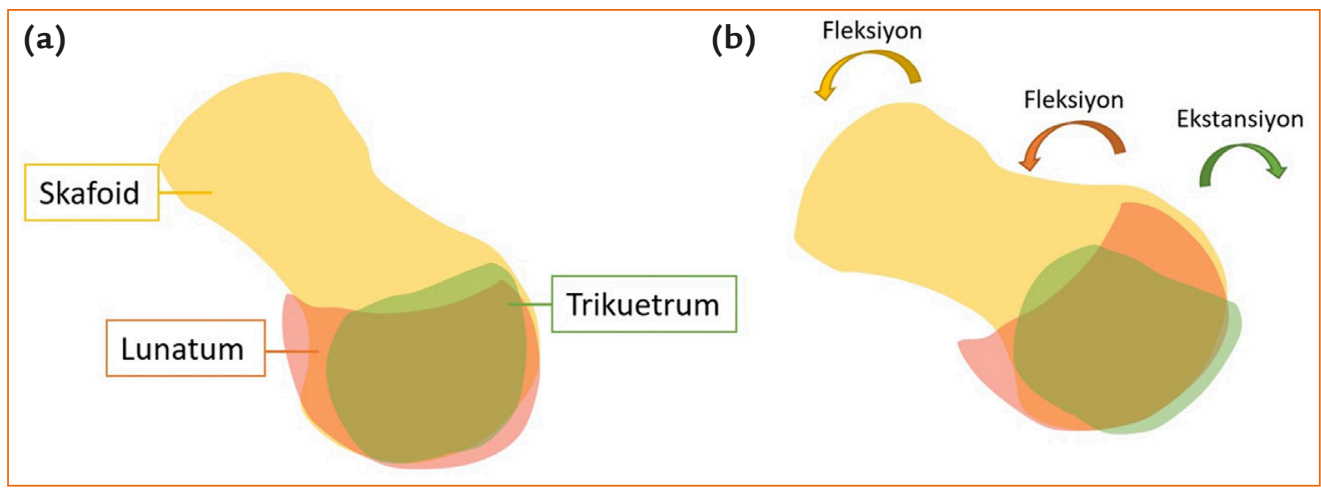

Şekil 2. a, b. Lateral görünüm, normal skafoid, lunatum ve trikuetrum dizilimi (a). VISI gelişimi; skafoid ve lunatum fleksiyona, trikuetrum ekstansiyona doğru yer değiştirmiş (b). 


\section{Klinik}

Lunotrikuetral bağ yırtıkları ulnar tarafta önemli ağrı sebeplerinden birisidir. Patoloji akut veya kronik ( 3 aydan uzun); travmatik veya dejeneratif olabilir. LT bağ lezyonları karpal çökme ya da perilunat instabiliteyle beraber olabilir. LT yaralanmaları şu şekilde sınıflandırılabiliir ${ }^{[6-8]}$ :

- Travmatik lokalize tip

- Travmatik ilerleyici perilunat instabilite

- Kronik-ulnokarpal dayanma

\section{Travmatik lokalize LT yaralanması}

En sık yaralanma şekli; el bileği aşırı ekstansiyon$\mathrm{da}$, avuç ulnar taraf üzerine düşme sonucu oluşur. Hipotenar çıkıntının yere çarpmasıyla pisiform ve trikuetrum dorsale deplase olurken lunatum güçlü radyokarpal bağlar nedeniyle hareketsiz kalır. Oluşan makaslama gücü LT bağın yırtılmasına yol açar. Bu tip yaralanmalara trikuetrum palmarindeki avülsiyon kırıkları eşlik edebilir. Travma sonrası palmarde trikuetrum avülsiyon kırı̆ı saptanan hastalarda mutlaka LT bağ muayene edilmelidir. ${ }^{[9-10]}$

\section{Travmatik ilerleyici perilunat instabilite}

Sıklıkla el bileğinde aşırı ekstansiyona yol açan yüksekten düşmeler ve motor kazaları sonrası gelişir. Perilunat yaralanmada hasar skafolunat bağdan başlar (evre 1) ve saat yönünün tersine lunokapitat bağa (evre 2), oradan lunotrikuetral bağa (evre 3 ) ve lunat çıkığına (evre 4) ilerler. ${ }^{[11]}$

\section{Ulnokarpal dayanma}

Uzun süreli ulnokarpal impaksiyon ilerleyici şekilde LT eklemde instabilite yaratır. Pozitif ulnar varyans, zamanla LT bağ proksimal membranöz kısımda yıpranmaya yol açar. Travmatik bir durum değildir. ${ }^{[12]}$

\section{Muayene}

Akut olgular, el palmar tarafına aldıkları darbe sonrası ağrı ve şişlik şikâyetiyle başvururlar. Şişlik travmayı takiben 2 hafta boyunca seyreder. Kronik olgular ise el bileği dorsoulnarinde ağıı atakları tarifler. Ağrı özellikle el bileğinin ekstansiyonu ve ulnar deviasyonuyla artar. Hastalarda ayrıca, kavrama gücünde azalma, el bileği hareketlerinde kısıtlanma, el bileğinden atlama sesi gelmesi ve ulnar sinir dağılımında uyuşma şikâyetleri olabilir.

Palpasyonla LT eklem üzerinde, ulnar enfiye çukuru içinde trikuetrum üzerinde hassasiyet oluşur. El bileği pronasyon ve ulnar devivasyondayken aksiyel yüklenmeyle ağrılı atlama hissi oluşabilir. El bileğine yapılan torsiyona zorlayıcı yüklenmelerde instabilite hissi doğar. Muayene el bileği radyal tarafını, midkarpal bölgeyi ve diğer el bileğini de içermelidir.

Muayene ve ayırıcı tanıda provokatif testler yararlıdır. Bu testler LT eklemde atlama hissi veya hareket olarak kendini gösterir. Diğer el bileğinin benzer bulgular göstermesi, genel laksite açısından anlamlıdır.

- Reagan ballotman testi: Pisotrikuetrum ünitesi bir elin baş ve işaret parmakları arasına, lunatum diğer elin baş ve işaret parmakları arasına alınır. LT eklem palmare ve dorsale doğru harekete zorlanır. LT eklemin hareketlenmesi veya ağrı durumunda test müspettir. ${ }^{[8]}$

- Kleinman makaslama testi: Lunatuma dorsalden başparmakla, pisiforma volarden başparmakla bastırılır. Lunatum ve trikuetrum arası hareketlenmede veya ağrıda test müspettir (pozitiftir). ${ }^{[13]}$

- Derby testi: Pisiforma volarden bastırılırken el bileğine dart artma hareketi yapılması istenir. Bu hareket sırasında atlama sesi veya ağrı gelişmesinde test müspettir. ${ }^{[14]}$

- Sennwald testi: Trikuetruma dorsalden başparmakla bastırılırken el bileği aşırı radyal tilte zorlanır. Trikuetrumda ağrıyla beraber subluksasyon gelişiyorsa test müspettir. ${ }^{[15]}$

Bu muayene yöntemlerine ek olarak, ağrı yerinin belirlenmesinde, radyokarpal veya midkarpal bölgeye yapılan lokal anestetik enjeksiyonları da yardımcı olabilir (Şekil 3).

\section{Radyoloji}

Statik radyografilerde tek başına interosseöz bağ yırtıkları bulgu vermez. Statik radyografilerde VISI görüldügünde, lunotrikuetral bağa ek olarak midkarpal bağların da etkilendiği düşünülmelidir. Hareketli floroskopi görüntüleri veya 4D kinematik BT incelemeleri dinamik instabilite teşhisinde kullanılabilir. Manyetik rezonans (MR) görüntüleme, LT bağ için halen tek başına yeterli bulgu vermeyebilir. MR'de, LT bağın stabilitede daha az öneme sahip proksimal membranöz kısmı, yüksek sıvı içeriği nedeniyle, baskın şekilde görünür. Stabilitede daha önemli olan dorsal ve volar fibröz kısmı ise MR'de iyi görüntülenmez. Dorsal kapsüler ayrışma, LT yaralanmanın indirekt bulgularından biri olabilir, MR artrografi ve artroskopi bu bölge için en yararlı görüntüleme yöntemidir. Her iki yöntem de yırtığın büyüklügünü ve beraberindeki triangular fibrokartilaj kompleks (TFKK) ve skafolunat bağ yırtıkları gibi lezyonları gösterebilir. ${ }^{[16,17]}$ 


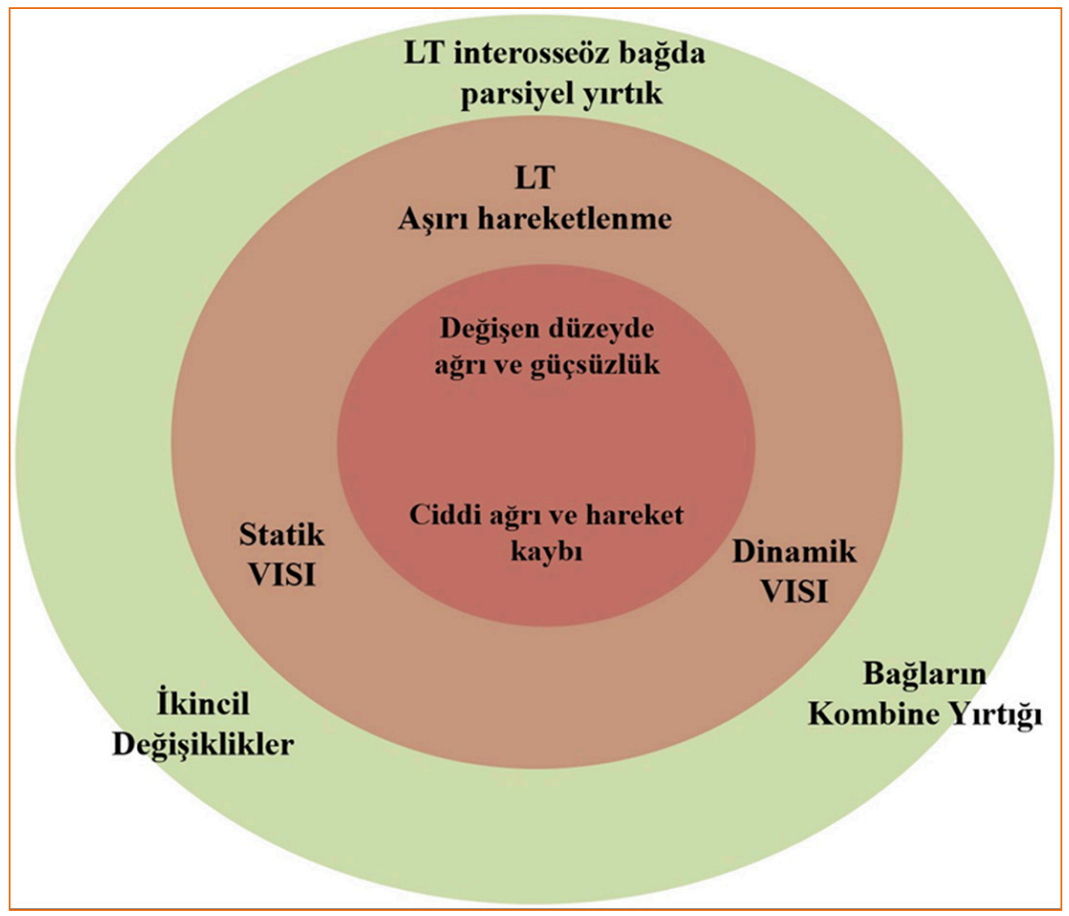

Şekil 3. Patoanatomi (yeşil daire), patomekanik (turuncu daire) ve klinik (kırmızı daire) ilişkisi.

\section{Tedavi}

Akut LT bağ yaralanması düşünülen (MRG'de ulnar taraf hasarı, muayene sırasında LT eklemde instabilite bulgusu) hastalara ilk 6 hafta nötral pozisyonda alçı veya atel ile konservatif tedavi uygulanabilir. Konservatif tedavi ve fizik tedavi sonrası şikâyetleri devam eden hastalara el bilek artroskopisi önerilebilir. ${ }^{[8]}$ Eğer yaralanma perilunat çıkık komponentlerinden birisi ise akut olarak bağ tamiri veya rekonstrüksiyonu uygun olur. Artroskopik LT bağ Geissler sınıflaması Tablo 1'de verilmiştir. ${ }^{[18]}$ Radyokarpal eklem muayenesinde membranöz kısımda hasarlanma ve ayrışma, dorsal ve volar sinovyal reaksiyon ve hipertrofi bize LT bağ hakkında bilgi verir. Bununla beraber instabilite tanısı genellikle midkarpal eklem artroskopisi ile konulur. LT bağ muayenesinde lunat ve trikuetrum eklem seviyelerinin eşitliği ve pisotrikuetral eklem üzerine baskı uygulanarak lunatum ve trikuetrum arası hareketlenme değerlendirilir. Probla yapılan muayene ile LT eklem instabilitesi değerlendirilir (Şekil 4). ${ }^{[19]}$

Tip 1 yırtıklarda; artroskopik LT eklem debridmanı ve büzüştürme veya dorsal ligamenttokapsülodez önerilir. ${ }^{[13,20]}$

Tip 2 yırtıklarda; artroskopik LT eklem redüksiyonu ve tespit veya dorsal ligamenttokapsülodez önerilir. ${ }^{[21]}$

Tablo 1. Geissler sınıflandırması ${ }^{[18]}$

\begin{tabular}{cl}
\hline Evre & Radyokarpal ve midkarpal artroskopik değerlendirme \\
\hline $\mathbf{1}$ & $\begin{array}{l}\text { Radyokarpal: İncelmiş, hemorajik interosseöz bağ } \\
\text { Midkarpal: Normal }\end{array}$ \\
$\mathbf{2}$ & $\begin{array}{l}\text { Radyokarpal: İncelmiş, hemorajik interosseöz bağ } \\
\text { Midkarpal: Skafolunat veya lunotrikuetral düzensizlik, basamak, minimal ayrışma (Prob kalınlığından az) }\end{array}$ \\
$\mathbf{3}$ & Hem radyokarpal hem midkarpal düzensizlik var. Prob interosseöz aralığa girer \\
$\mathbf{4}$ & Radyokarpal ve midkarpal interosseöz belirgin ayrışma, artroskop radyokarpal aralıktan midkarpal aralığa girer
\end{tabular}



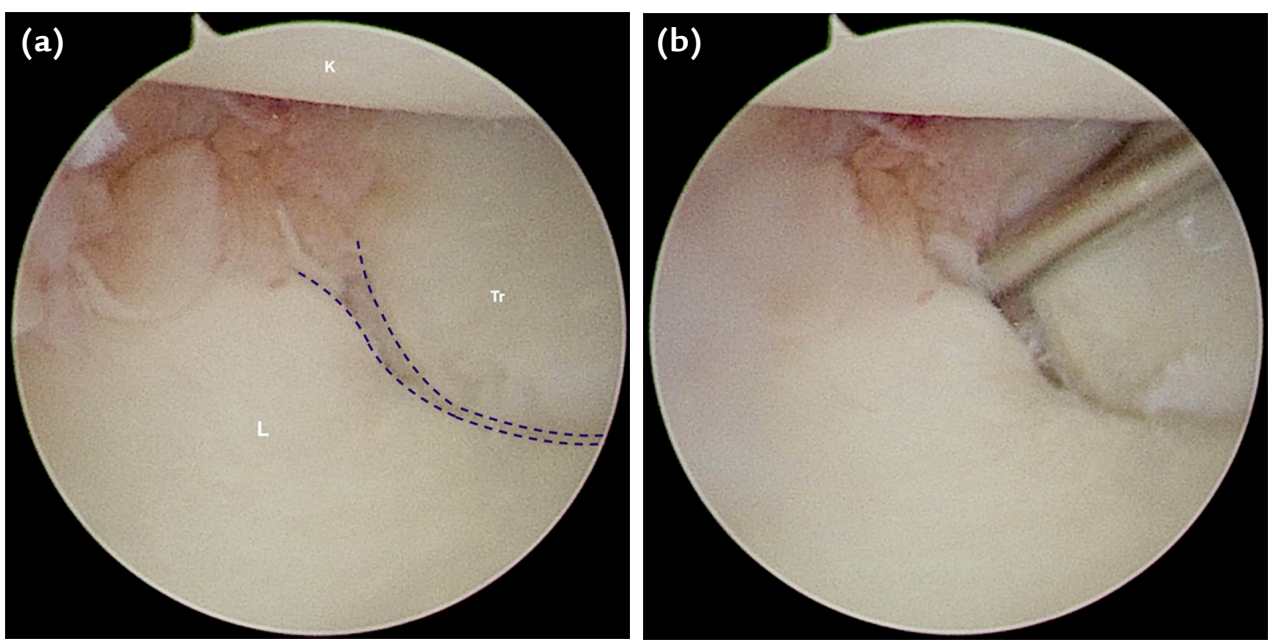

Şekil 4. a, b. Lunotrikuetral ayrışmada artroskopik görüntü: Midkarpal eklemden lunatum (L), trikuetrum ( $\mathrm{Tr}$ ) ve kapitatumun (K) görünümü (a). Lunatum ile trikuetrum arasına probun rahatlıkla girdiği görülmektedir, Geissler tip 3 yırtık (b).
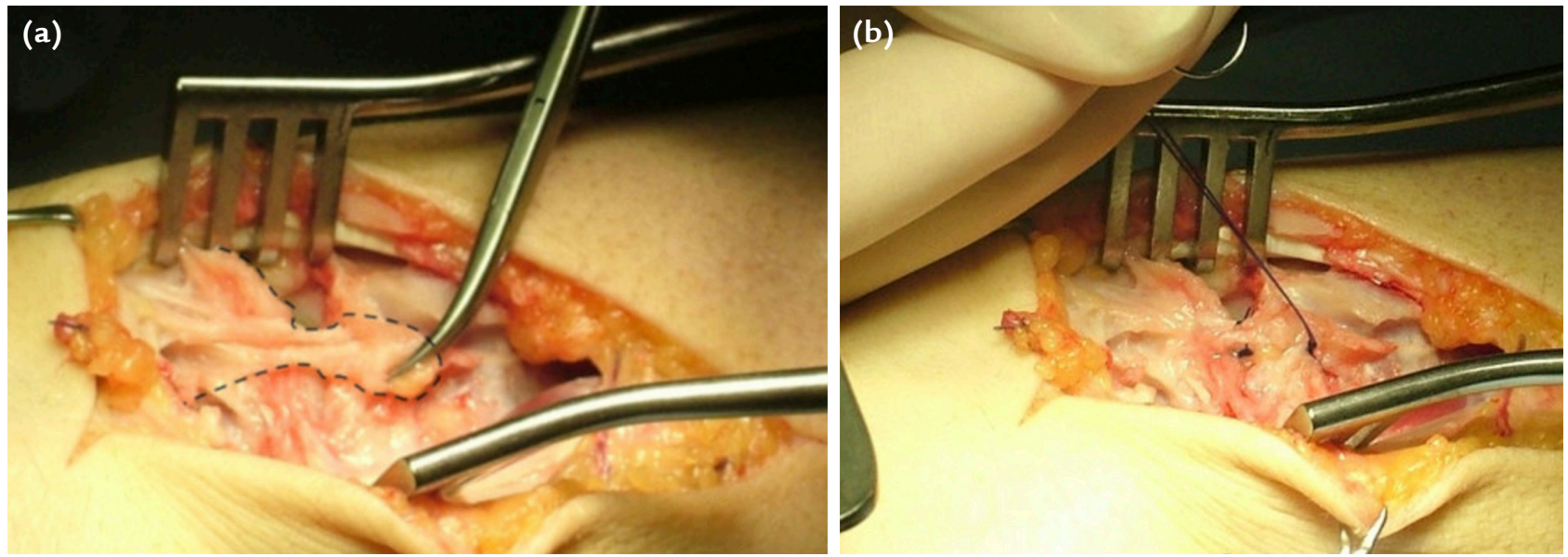

Şekil 5. a, b. LT eklem dorsal ligamentokapsülodez: El bileği dorsalinden yapılan yaklaşım sonrası dorsal kapsül flep şeklinde kaldırılmış (kesikli çizgi) (a). Kaldırılan kapsül flebi iki adet kemik çapayla (1,5 mm) lunatuma dikilmiş (b).

Dorsal ligamentokapsülodez tekniği şu şekildedir: Kola turnike sarılır ve parmaklardan traksiyon yapılır. 3-4, 6R, midkarpal radyal (midkarpal-R) ve midkarpal ulnar (midkarpal-U) portallar açılır. Dorsal kapsüldeki ayrışma değerlendirilir. Midkarpal-R portalinden, skafolunat, LT bağlar ve midkarpal eklemler muayene edilir. Radyokarpal aralıktan yerleştirilen tıraşlayıcı (shaver) ile LT eklem debride edilir. Sonrasında artroskop 3-4 portalına alınır ve $6 \mathrm{R}$ portalından girilerek dorsal eklem kapsülünden 18G iğneyle iki adet 3/0 PDS (p-dioksanone) iplik geçirilir. Artroskop midkarpal-R portalına alınır, dorsal kapsülden geçirilen ipliklerin ucu midkarpal-U portalından çıkarılır. İplik uçlarının her iki ucuna dügüum atılır ve LT ekleme kaydırılarak oturtulur. Traksiyon gevşetildikten sonra el bileği en az $30^{\circ}$ ekstansiyonda düğümler sıkılır. Altı hafta boyunca el bileği $40^{\circ}$ ekstansiyonda dirsek altı ateline alınır. Sonrasında rehabilitasyon programına yönlendilir.

Tip 3 yırtıklarda; açık LT bağ tamiri veya artroskopik dorsal ligamentokapsulodez önerilir. Artroskopik dorsal ligamentokapsülodez sıkça uygulanan tedavi yöntemi olmakla beraber açık cerrahi teknik de kullanılabilir. LT eklem çevresi sinovyal dokular temizlenir, Kirschner (K) tellerinin manipülasyonuyla lunatum ve trikuetrum redükte edilir. LT bağ transosseöz dikişler veya çapa sütürlerle onarılır. Trikuetrum ve lunatum arası ve de trikuetrumdan kapitatuma K-telleri yerleştirilir. Dorsal kapsül sıkıca onarılır. K-telleri ve dirsek üstü atel 6-8 hafta tutulur (Şekil 5). ${ }^{[22-24]}$ 
Tip 4 yırtıklarda; yine tespit ve bağın artroskopik veya açık yöntemler ile rekonstrüksiyonu denenebilir. Tedavi başarısız olan olgularda eğer LT eklemde artrozik değişiklikleri olmuşsa artroskopik veya açık LT eklem artrodezi yapılabilir. [19]

Lunotikuetral eklem yaralanmalarında mutlaka pozitif ulnar varyans, TFKK santral dejeneratif yırtık ve ulnar impaksiyon değerlendirilmeli ve gereğinde tedavi edilmelidir.

\section{SONUÇ}

Lunotikuetral bağ hasarlanmaları el bileği ulnar taraf ağrı nedenlerinin önemli bir kısmını oluşturur. Özellikle ulnar impaksiyon olgularında LT bağ hasarlanması şüphesi ile LT eklem mutlaka kontrol edilmelidir. Tanıda MRG her zaman yeterli bulgu vermeyebilir. Dinamik radyografi ve kinemetik BT incelemeleri tanıya eklenebilir ama tanıda altın standart artroskopidir. Artroskopik tedavi yöntemleri son yıllarda tedavide kullanılmakla beraber açık bağ tamiri, bağ rekonstrüksiyonu, kapsülodez, artroskopik veya açık artrodez gibi tedavi yöntemleri kullanılabilir.

\section{KAYNAKLAR}

1. Ritt MJ, Bishop AT, Berger RA, Linscheid RL, Berglund LJ, An KN. Lunotriquetral ligament properties: a comparison of three anatomic subregions. J Hand Surg Am 1998;23(3):42531. Crossref

2. Berger RA. The anatomy of the ligaments of the wrist and distal radioulnar joints. Clin Orthop Relat Res 2001;383:3240. Crossref

3. Ritt MJ, Linscheid RL, Cooney III WP, Berger RA, An KN. The lunotriquetral joint: kinematic effects of sequential ligament sectioning, ligament repair, and arthrodesis. J Hand Surg Am 1998;23(3):432-45. Crossref

4. Lee DJ, Elfar JC. Carpal Ligament Injuries, Pathomechanics, and Classification. Hand Clin 2015;31(3):389-98. Crossref

5. Horii E, Garcia-Elias M, An KN, Bishop AT, Cooney WP, Linscheid RL, Chao EY. A kinematic study of luno-triquetral dissociations. J Hand Surg Am 1991;16(2):355-62. Crossref

6. Linscheid RL, Dobyns JH, Beabout JW, Bryan RS. Traumatic instability of the wrist. Diagnosis, classification, and pathomechanics. J Bone Joint Surg Am 1972;54(8):1612-32. Crossref

7. Garcia-Elias M. Lésions du complexe lunotriquetral: principes thérapeutiques [Lunar-triquetral complex lesions: therapeutic principles]. Chir Main 2003;22(2):57-64. Crossref
8. Reagan DS, Linscheid RL, Dobyns JH. Lunotriquetral sprains. J Hand Surg Am 1984;9(4):502-14. Crossref

9. Smith DK, Murray PM. Avulsion fractures of the volar aspect of triquetral bone of the wrist: a subtle sign of carpal ligament injury. AJR Am J Roentgenol 1996;166(3):609-14. Crossref

10. Becce F, Theumann N, Bollmann C, Omoumi P, Richarme D, Guerini H, Campagna R, Meuli R, Drapé JL. Dorsal fractures of the triquetrum: MRI findings with an emphasis on dorsal carpal ligament injuries. AJR Am J Roentgenol 2013;200(3):608-17. Crossref

11. Mayfield JK, Johnson RP, Kilcoyne RK. Carpal dislocations: pathomechanics and progressive perilunar instability. J Hand Surg Am 1980;5(3):226-41. Crossref

12. Gupta R, Bingenheimer E, Fornalski S, McGarry $\mathrm{MH}$, Osterman AL, Lee TQ. The effect of ulnar shortening on lunate and triquetrum motion -a cadaveric study. Clin Biomech (Bristol, Avon) 2005;20(8):839-45. Crossref

13. Weiss LE, Taras JS, Sweet S, Osterman AL. Lunotriquetral injuries in the athlete. Hand Clin 2000;16(3):433-8. Crossref

14. Christodoulou L, Bainbridge LC. Clinical diagnosis of triquetrolunate ligament injuries. J Hand Surg $\mathrm{Br}$ 1999;24(5):598-600. Crossref

15. Sennwald GR, Fischer M, Mondi P. Lunotriquetral arthrodesis: acontroversial procedure. J Hand Surg Br 1995;20(6):75560. Crossref

16. Lichtman DM, Noble 3rd WH, Alexander CE. Dynamic triquetrolunate instability: Case report. J Hand Surg Am 1984;9(2):185-8. Crossref

17. Shin AY, Battaglia MJ, Bisphop AT. Lunotriquetral instability: Diagnosis and treatment. J Am Acad Orthop Surg 2000;8(3):170-9. Crossref

18. Geissler WB, Burkett JL. Ligamentous sports injuries of the hand and wrist. Sports Med Arthrosc Rev 2014;22(1):39-44. Crossref

19. van de Grift TC, Ritt MJ. Management of lunotriquetral instability: a review of the literature. J Hand Surg $\mathrm{Br}$ 2016;41(1):72-85. Crossref

20. Ruch DS, Poehling GG. Arthroscopic management of partial scapholunate and lunotriquetral injuries of the wrist. J Hand Surg Am 1996;21(3):412-7. Crossref

21. Osterman AL, Seidman GD. The role of arthroscopy in the treatment of lunatotriquetral ligament injuries. Hand Clin 1995;11(1):41-50. Crossref

22. Shin AY, Bishop AT. Treatment options for lunotriquetral dissociation. Tech Hand Up Extrem Surg 1998;2(1):2-17. Crossref

23. Omokawa S, Fujitani R, Inada Y. Dorsal radiocarpal ligament capsulodesis for chronic dynamic lunotriquetral instability. J Hand Surg Am 2009;34(2):237-43. Crossref

24. Acar MA, Özdemir A, Eravsar E. Arthroscopic dorsal capsulodesis for isolated lunotriquetral interosseous ligament injuries. J Hand Surg Br 2021;17:1753193420983687. Crossref 